\title{
A Comparative Study of the Effects of Pulp Fractionation, Refining, and Microfibrillated Cellulose Addition on Tissue Paper Properties
}

\begin{abstract}
Jérémie Viguié, ${ }^{\mathrm{a}, \mathrm{b}, *}$ Saurabh Kumar, ${ }^{\mathrm{b}}$ and Bruno Carré ${ }^{\mathrm{b}}$
Environmental and economic concerns are driving tissue paper manufacturers to improve understanding of the relationships between fibres, the networks they form, the forming process, and the final tissue paper properties. This work investigated how pulp fractionation, refining, or addition of microfibrillated cellulose (MFC) affect the compromise between absorbency and strength of $33 \pm 2 \mathrm{~g} / \mathrm{m}^{2}$ model papers made of bleached eucalyptus kraft pulp. The results showed that the compromise of properties was better when fibres were refined than when MFC was added. The absorbency capacity of $2 \%$ wt MFC-paper was almost $20 \%$ lower than the capacity of the refined paper at the same dry strength. The calculated additional storage capacity due to water-induced deformations of the fibre network was $40 \%$ lower in the same range of bulk. By forming a high viscosity gel at inter-fibre contacts, MFC could limit the occurrence of major fibre and network deformation mechanisms when water was imbibing the paper.
\end{abstract}

DOI: 10.15376/biores.17.1.1507-1517

Keywords: Absorbency capacity; Pulp fractionation; Refining; Micro-fibrillated cellulose; Network swelling ability; Tissue paper

Contact information: a: Univ. Grenoble Alpes, CNRS, Grenoble INP, LGP2, F-38000 Grenoble, France; b: Centre Technique du Papier (CTP), F-38044 Grenoble, France;

*Corresponding author: jeremie.viguie@lgp2.grenoble-inp.fr

\section{INTRODUCTION}

Environmental and economic concerns are driving tissue paper manufacturers to minimize energy consumption and the use of resources while maintaining tissue paper performance. This makes it necessary to improve the understanding of the relationships between fibres, the networks that they form, the forming process, and the three main properties of tissue paper: absorbency, strength, and softness (Abedsoltan 2017).

The absorbency capacity of tissue paper is related to the storage capacity of its porous structure formed during the papermaking process (Hsieh 1995; Sayeb et al. 2013). This porous structure depends on forming and drying conditions (creping, structured fabrics, TAD, etc.) (De Assis et al. 2018) and on fibre properties such as morphology or conformability (Steadman and Luner 1985; He et al. 2003; Niskanen 2011). However, fibre swelling and softening phenomena induced by water absorption may lead to more or less significant deformations of the porous structure, impacting the final absorbency capacity of paper (Hubbe et al. 2013).

As for standard papers, mechanical strength of tissue papers can be improved by pulp refining. In the refining process, fibers are subjected to compression and shear forces. These forces cause several changes in fibres: removal of primary wall, delamination and 
swelling of the secondary wall (internal fibrillation) that improves fibre flexibility (Pulkkinen and Fiskari 2008), and peeling off the fibrils from the fiber surface (external fibrillation). Such peeling improves the potential bonding area and producing fines (fragments with size less than $76 \mu \mathrm{m}$ ) that may act as bonding bridges at inter-fibre contacts (Antonsson et al. 2009; Gharehkhani et al. 2015). However, refining contributes to reduced absorbency capacity of paper, mainly by increasing the density of the fibre network (Gigac and Fišerová 2008; Kullander et al. 2012). Therefore, tissue manufacturers have to adjust refining to find the right compromise between absorbency and strength. Recently microfibrillated cellulose (MFC) addition was found to impact paper properties in the same way: bulk and absorbency capacity decrease while strength increases with the MFC content (Morais et al. 2021; Zambrano et al. 2021). However, to the authors' knowledge, no academic study has been carried out on the comparison of the effect of MFC with the effect of refining on the compromise of properties.

Hydrocyclone fractionation and separate refining of fractions have been found to be relevant to optimize the compromise between the production cost and the mechanical performance of graphic papers (Huber et al. 2018). Hydrocyclone fractionation permits the separation of fibres depending on their extent of development (related to following parameters: wall thickness, stiffness, fibrillation, etc.), resulting from their different migration behaviour in the centrifugal flow field. To date, no study has been dedicated to the effect of fractionation and separate refining of fractions on the compromise of properties of a monolayer tissue base sheet (after remixing of fractions) or a multilayer structure (where each fraction forms a layer).

This study examined how pulp fractionation, refining, or MFC addition affect the compromise between absorbency capacity and dry tensile strength of $33 \pm 2 \mathrm{~g} / \mathrm{m}^{2}$ model papers from eucalyptus kraft pulp. Then, the approach of separate refining of selected fractions was investigated for such papers. Note that the model papers were not creped. It might be an issue to conclude on the actual effects on tissue (i.e., creped) paper. However, De Assis et al. (2020) recently found a reasonable correlation between the performances of uncreped and creped handsheets.

\section{EXPERIMENTAL}

\section{Materials}

Pulp

The pulp was a $100 \%$ bleached eucalyptus kraft pulp from Brazil. The pulp was slushed in a low consistency pulper ( $5 \%$ consistency, $\left.30 \mathrm{~min}, 45^{\circ} \mathrm{C}\right)$. The pulp had an initial drainage index of $17^{\circ} \mathrm{SR}$. No wet-end additives were used.

\section{Model papers}

Model papers were produced on an automated dynamic laboratory sheet former (Techpap, Grenoble, France). Sheets were all manufactured with a $33 \pm 2 \mathrm{~g} / \mathrm{m}^{2}$ grammage, with a ratio of jet speed/wire speed equal to 0.652 , so that the fibres were preferentially oriented in the machine direction. Sheets $\left(240 \times 880 \mathrm{~mm}^{2}\right)$ were slightly pressed to be removed from the wire using a cylindrical roll of $500 \mathrm{~g}$. They were air-dried without any pressure, sandwiched at the four edges between PVC plates to prevent drying shrinkage. 


\section{Micro-fibrillated cellulose}

Micro-fibrillated cellulose (MFC) has been produced at Centre Technique du Papier (CTP) from a birch kraft pulp (BKP) (Meyer et al. 2012). The pulp was pre-refined at $3.5 \mathrm{wt} \%$ to $25^{\circ} \mathrm{SR}$, enzymatically treated with endoglucanase (FiberCare R, Novozymes, Bagsvaerd, Denmark) at $0.1 \mathrm{~kg} / \mathrm{t}$ during $1 \mathrm{~h}$ at $50{ }^{\circ} \mathrm{C}$ and $\mathrm{pH} 5$, post-refined to $80^{\circ} \mathrm{SR}$, diluted to $2 \mathrm{wt} \%$, and mechanically treated by high-shear homogenization on a pilot scale homogenizer from GEA Niro-Soavi. The homogenization consisted of a first pass at 500 bars, a second pass at 1000 bars, and 4 subsequent passes at 1500 bars. An optical micrograph of the suspension is presented in Fig. 1. The residual fibre and fine contents measured with a Morfi fibre analyser (Techpap, France) in the MFC suspension are presented in Table 1 . A comparison was done with the unrefined and $80^{\circ} \mathrm{SR}$ refined BKP. The amount of fibres increased with refining corresponding to the separation of large fibres into smaller fibres, as evidenced by a tripled fines content. Then, the fibre content of the MFC suspension highly decreased. Fibres were not just converted into smaller fibres, but rather into fines or fibrils having a diameter inferior to the detection limit $(3 \mu \mathrm{m})$, as revealed by the decreasing amount of both fibres and fines.

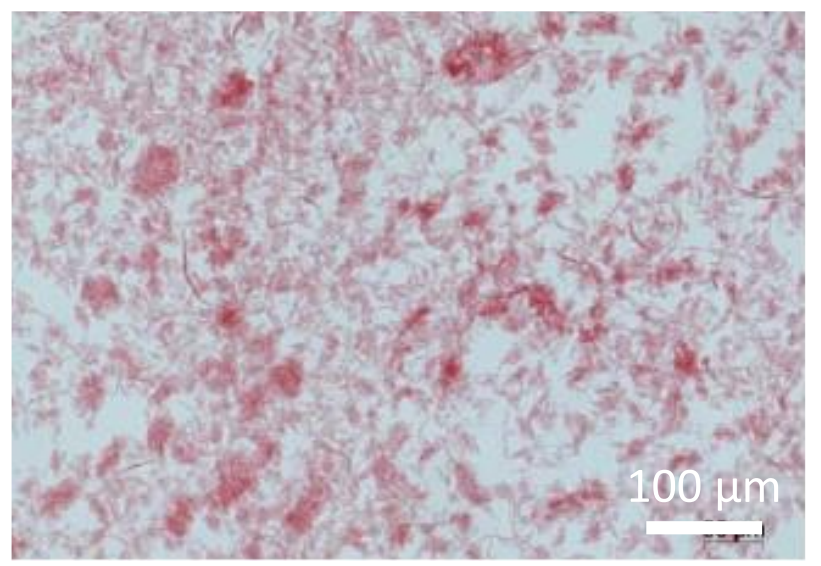

Fig. 1. Optical microscopic picture of the MFC suspension coloured with Congo Red

Table 1. Fibre and Fines Contents in the Raw BKP, after Refining at $80^{\circ} \mathrm{SR}$, and in the MFC Suspension

\begin{tabular}{|c|c|c|c|}
\hline & BKP & Refined $\left(80^{\circ} \mathrm{SR}\right)$ & MFC \\
\hline $\begin{array}{c}\text { Fibre Content } \\
\text { (millions/g of pulp) }\end{array}$ & $30.5 \pm 1.0$ & $58.6 \pm 2.2$ & $3.4 \pm 0.2$ \\
\hline $\begin{array}{c}\text { Fine Content } \\
\text { (millions/g of pulp) }\end{array}$ & $121 \pm 5$ & $368 \pm 11$ & $211 \pm 8$ \\
\hline
\end{tabular}

\section{Methods}

\section{Pulp fractionation}

A 2-stage feed-forward hydrocyclone fractionation was performed. The pilot trials were done with an $80 \mathrm{~mm}$ head diameter industrial fractionating hydrocyclone (NOSS AM80H). Conditions are described in Fig. 2. The two-stage feed forward fractionation was performed batch-wise, with the same single hydrocyclone being used for both the stages. Due to limited storage capacity, the $1^{\text {st }}$ stage hydrocyclone base fraction was thickened on the pilot vacuum filter. The filter offers high fibre and fines retention. This thickened base fraction was added to the $2^{\text {nd }}$ stage base fraction to get a combined fraction and then 
thickened on the same vacuum filter. The other fraction, i.e. the apex fraction, was collected and thickened using a laboratory centrifugation device, hence retaining all cellulosic elements.

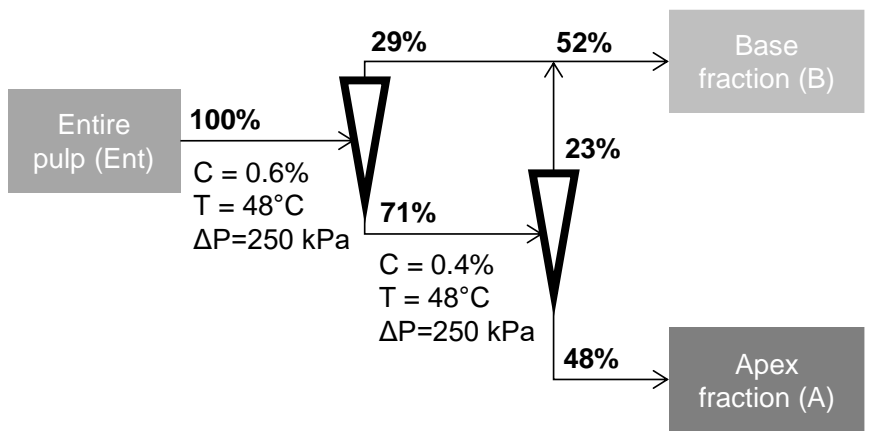

Fig. 2. Schematic and conditions of the fractionation process

\section{Pulp refining}

The feed pulp (Ent), the apex fraction (A), and the base fraction (B) were refined separately, using the same conditions. A 12" single disc refiner pilot system described in (Lecourt et al. 2011) was used. The disc refiner was equipped with a plate pattern allowing reaching a specific edge load of $0.4 \mathrm{Ws} / \mathrm{m}$. Energy applied was calculated by dividing net power applied $(\mathrm{kW})$ by mass flow (dry $\mathrm{T} / \mathrm{h})$. It should be noted that in general different refining strategies are applied to refine different fractions, especially in view of optimizing the energy consumption. Here the objective was different and consisted of comparing the properties of fractions with each other at same refining conditions.

\section{Characterizations}

Morphological properties

The properties of the pulp and fractions relevant for the study (mean fibre length, mean fibre width, fine content, macrofibrillation index) were measured with a Morfi fibre analyser (Techpap, France) through image analysis. Note that the macrofibrillation index, which characterizes the external fibrillation, represents the ratio of total fibrils length to the total fibre+fibrils length (down to a scale of $3 \mu \mathrm{m}$ ).

\section{Sheet physical properties}

The sheet physical properties were assessed using the following standard methods: pre-conditioning (NF EN 20 187, 1993), basis weight (NF EN ISO 536, 1996), and dry and wet tensile properties (ISO 12625-4 and ISO 12625-5). The measurements of the thickness of the laboratory papers were performed following the ISO Standard 12625-3 on a FranckPTI universal micrometer (Austria) by applying a load of $2 \mathrm{kPa}$ adapted to compressible materials.

\section{Absorbency capacity}

The absorbency tests were performed according to the ISO Standard 12625-8. This method consists in putting a tissue sample into a standardized immersion basket. The sample was weighed together with the basket. The basket dropped into a water basin, which was filled with distilled water. There, the sample sank and remained for 30 seconds in water, and subsequently was lifted to stay for $1 \mathrm{~min}$ at a defined angle to drain. After this, the sample and the basket were weighted again. The operator defined the water absorbency 
capacity. In this study, the quantity of used tissue was reduced (around $0.5 \mathrm{~g}$ ) in order to consider only the water absorption inside the fibre network (i.e. intra-sheet water, no between two adjacent paper sheets).

\section{RESULTS}

Fibre morphology data of the entire pulp (Ent), the apex fraction $(A)$, and the base fraction $(B)$ are presented in Table 2 . The used fractionation approach is known to separate fibres following how flexible they are and/or fibrillated and/or composed of fines (Huber et al. 2018). Accordingly, the external fibrillation of the $B$ fibres was two times higher than the external fibrillation of the $A$ fibres.

Table 2. Morphological Properties of Fibres of the Entire Pulp (Ent), the Apex Fraction $(A)$, and the Base Fraction $(B)$ at Various Levels of Refining Energy (40 and $80 \mathrm{Kwh} / \mathrm{T}$ ), and Physical Properties of Model Papers Obtained with Different Fibre Types

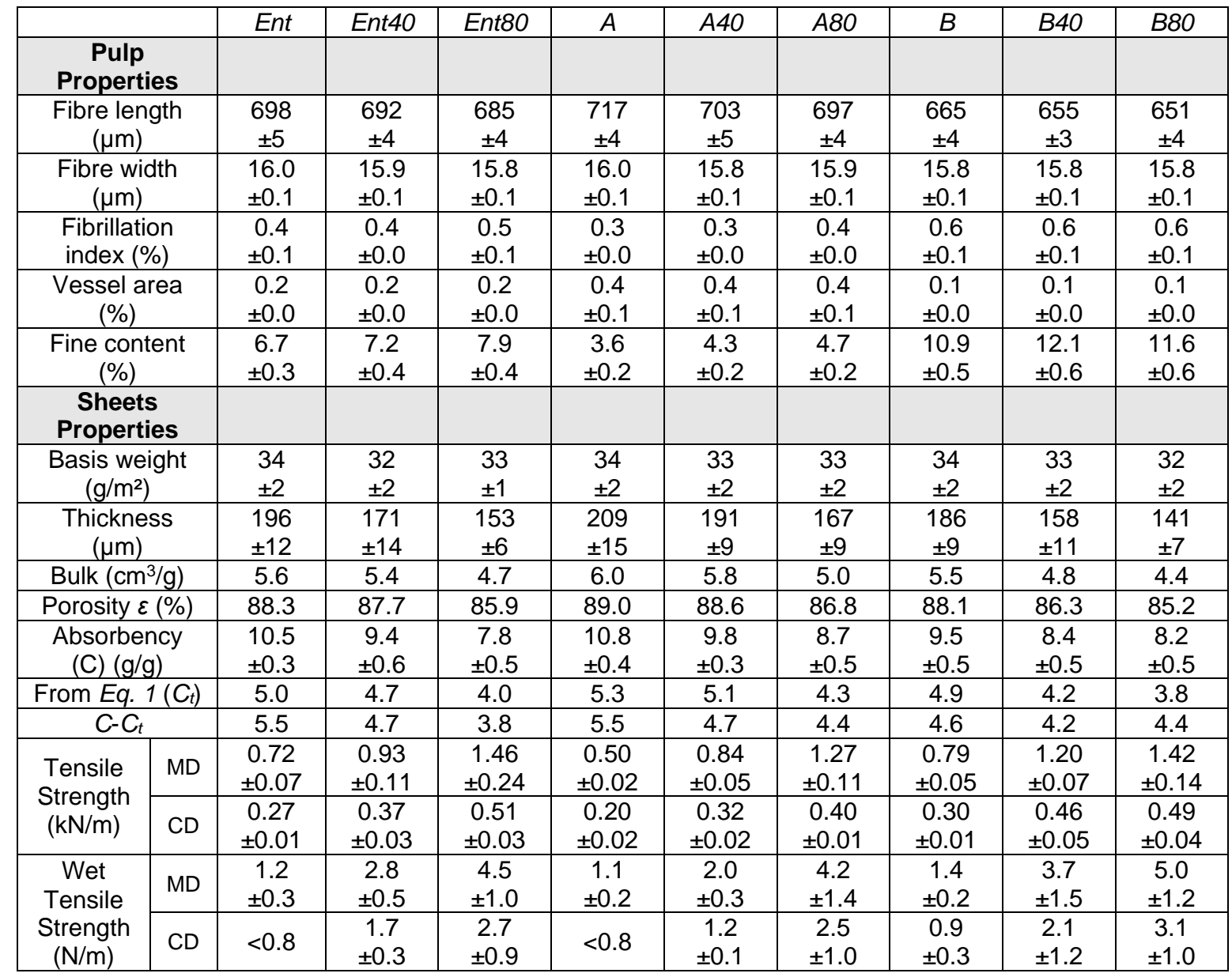


The fines content was close to three times higher. In addition, the fractionation process seemed to concentrate the vessels in the $A$ fraction. However, it did not discriminate the eucalyptus fibres according to their width. As expected, $A$ fibers formed bulkier papers, whereas $B$ fibers formed denser networks than Ent fibers (Table 2). The highest value of absorbency capacity was reached for the $A$ paper and the lowest for the $B$ paper. The Ent paper reached an intermediate value. This was in accordance with the evolution of the bulk: the lower the porosity, the lower the space available for water and the lower the absorbency capacity. As expected, the dry tensile strength evolved in the opposite way (Table 2): the lower the bulk, the higher the number of inter-fibre contacts, the higher the bonding area and the higher the dry tensile strength (Niskanen 1998). Note that the more fibrillated fibres of the $B$ paper may also contribute to strengthen the fibre network by promoting bonding. As no wet additives were added, the wet strength was very low. However, it followed the same evolution trend as the dry strength.

Two levels of refining energy of 40 and $80 \mathrm{kWh} / \mathrm{t}$ were applied to the entire pulp $(E n t)$, the base fraction $(B)$ and the apex fraction $(A)$. These levels are rather low and in the range of levels traditionally applied to tissue paper pulps.

The fibre morphology data and paper sheet properties are presented in Table 2. According to the well-known refining effects (wall delamination, peeling off the fibrils from the fiber surface and removing of wall fragments), the fines content increased and the paper bulk decreased regardless of the fraction (Gharehkhani et al. 2015). Note that the fibre length and the macrofibrillation index were only slightly affected. As shown in previous studies (Gigac et al. 2008; Kullander et al. 2012), the absorbency capacity decreased while the tensile strength increased with refining (Table 2). It should be noted that these data were in line with the literature on uncreped handsheets (De Assis 2020). The absorbency capacity of the same paper after creping can be expected to be around $30 \%$ higher and tensile strength around 70\% lower (De Assis 2020). To highlight the effects of fractionation and refining on the compromise of properties (absorbency $v s$ strength), the absorbency capacity was plotted as a function of the mean tensile strength in Fig. 3.

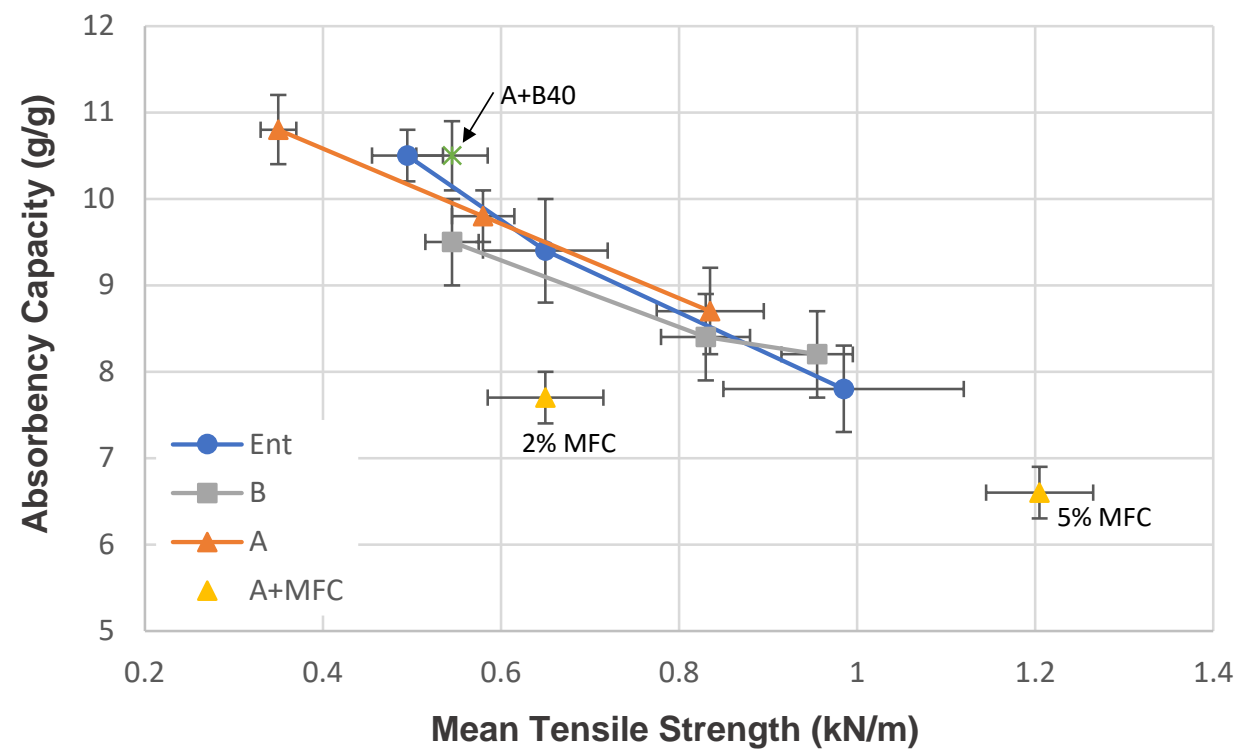

Fig. 3. Absorbency capacity as a function of mean dry tensile strength (between MD and CD) for the Ent, $B$ and $A$ papers at the different refining levels, the $A$ paper with MFC and the paper made of two fractions mixture $A+B 40$ 
Considering standard deviations, all the points almost belonged to the same evolution curve. This suggests that a specific performance level in absorbency capacity is associated with a specific performance level in tensile strength regardless of the operation fibres were subjected to (fractionation and/or refining).

The effect of MFC was investigated by adding $2 \mathrm{wt} \%$ and $5 \mathrm{wt} \%$ to $A$. The paper sheet properties are presented in Table 3. MFC addition led to sheet densification and tensile strength improvement as observed by several authors (Ankerfors et al. 2017). Absorbency was greatly reduced by MFC addition. This was in accordance with results from recent works (Zambrano et al. 2021; Morais et al. 2021). Values were plotted in Fig. 3 . For the same range of dry tensile strength, the absorbency capacity of MFC-papers (at 2 wt $\%$ ) was almost $20 \%$ lower than the capacity of the fractionated/refined papers. This suggested that the compromise of properties was less good with MFC addition. Note that the wet tensile strength of MFC-papers seemed to be slightly higher (for the same range of dry strength). However, values were too low to conclude a real trend.

Finally, the effect of only refining the $B$ fraction on the performance of the mixture was studied. $A$ was mixed with the $B 40$ fraction (refined at $40 \mathrm{kWh} / \mathrm{t}$ ). Sheet properties are presented in Table 3 . It was also plotted in Fig. 3 . The $A+B 40$ paper was slightly higher than the mean evolution curve. This result suggested that the compromise of properties could be adjusted by only refining the accepts fraction.

Table 3. Physical Properties of Model Papers Obtained from Different Fibre Blends: The Apex Fraction $(A)$ with 2 wt\% and 5 wt\% of Microfibrillated Cellulose (MFC), the Mixture (50\%/50\%) of $A$ with the Base Fraction $(B)$ Refined at 40 $\mathrm{kWh} / \mathrm{t}$

\begin{tabular}{|c|c|c|c|c|c|}
\hline \multirow{2}{*}{\multicolumn{2}{|c|}{ Sheets Properties }} & $A$ & $A+2 \% \mathrm{MFC}$ & $A+5 \% \mathrm{MFC}$ & $A+B 40$ \\
\hline & & & & & \\
\hline \multicolumn{2}{|l|}{ Basis weight $\left(\mathrm{g} / \mathrm{m}^{2}\right)$} & $34 \pm 2$ & $33 \pm 2$ & $34 \pm 2$ & $33 \pm 1$ \\
\hline \multicolumn{2}{|l|}{ Thickness $(\mu \mathrm{m})$} & $209 \pm 15$ & $190 \pm 11$ & $157 \pm 3$ & $186 \pm 15$ \\
\hline \multicolumn{2}{|l|}{ Bulk $\left(\mathrm{cm}^{3} / \mathrm{g}\right)$} & 6.0 & 5.8 & 4.5 & 5.6 \\
\hline \multicolumn{2}{|l|}{ Porosity $\varepsilon(\%)$} & 89.0 & 88.6 & 85.2 & 88.2 \\
\hline \multicolumn{2}{|l|}{ Absorbency $(\mathrm{g} / \mathrm{g})(C)$} & $10.8 \pm 0.4$ & $7.7 \pm 0.3$ & $6.6 \pm 0.3$ & $10.5 \pm 0.4$ \\
\hline \multicolumn{2}{|l|}{$C_{t}$ from Eq. 1} & 5.3 & 5.1 & 3.8 & 5.0 \\
\hline \multicolumn{2}{|l|}{$C-C_{t}$} & 5.5 & 2.6 & 2.8 & 5.5 \\
\hline \multirow{2}{*}{$\begin{array}{l}\text { Tensile Strength } \\
(\mathrm{kN} / \mathrm{m})\end{array}$} & MD & $0.50 \pm 0.02$ & $0.98 \pm 0.10$ & $1.86 \pm 0.07$ & $0.80 \pm 0.05$ \\
\hline & CD & $0.20 \pm 0.02$ & $0.32 \pm 0.03$ & $0.55 \pm 0.05$ & $0.29 \pm 0.03$ \\
\hline \multirow{2}{*}{$\begin{array}{l}\text { Wet Tensile Strength } \\
(\mathrm{N} / \mathrm{m})\end{array}$} & MD & $1.1 \pm 0.2$ & $3.2 \pm 1.0$ & $6.0 \pm 1.8$ & $2.8 \pm 0.9$ \\
\hline & CD & $<0.8$ & $1.8 \pm 0.8$ & $3.1 \pm 1.0$ & $1.6 \pm 0.5$ \\
\hline
\end{tabular}

\section{Absorbency and Strength vs. Bulk}

In an attempt to understand why fractionated/refined papers and MFC-papers behaved differently, the absorbency capacity and the mean tensile strength were plotted as a function of the bulk in Fig. 4a and 4b, respectively. At same bulk, the absorbency capacity of the MFC-papers was significantly lower than the capacity of the refined papers $(-20 \%$ at $2 \%$ MFC, see red arrow), whereas the mean tensile strength was improved to a lesser extent $(+10 \%$, at $2 \% \mathrm{MFC}$, see red arrow). 

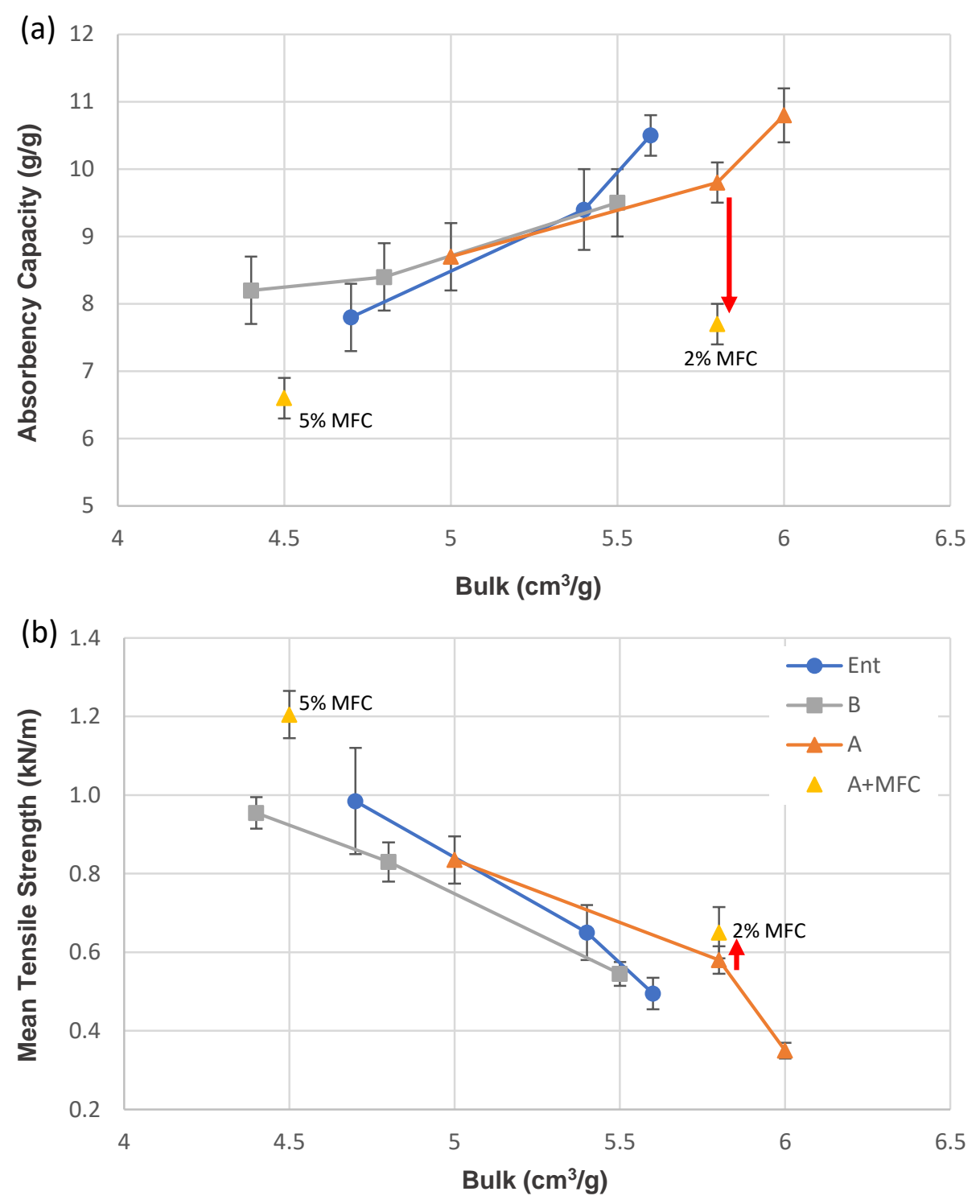

Fig. 4. (a) Absorbency capacity and (b) mean tensile strength as a function of bulk for the Ent, $B$ and $A$ papers at the different refining levels and the $A$ paper with MFC

The theoretical storage capacity of the porous structure $\left(C_{t}\right)$ was assessed as if fibres were not sensitive to water (did not swell and remained stiff) and all the pores were filled with water, using Eq. 1, where $\varepsilon$ is the porosity calculated from the bulk and the cellulose density ( $\left.\rho_{\text {cell }}\right)$ (Sayeb et al. 2013).

$$
C_{t}=\frac{\rho_{\text {water }}}{\rho_{\text {cell }}}\left(\frac{\varepsilon}{1-\varepsilon}\right)
$$

The $C_{t}$ values are listed in Tables 2 and 3 . It is worth noting that they were lower than the experimental absorbency capacity values $(C)$, attesting to the fact that waterinduced deformations of the fibre network led to an improvement of the storage capacity of the paper structure. These deformations may result from fibre wall swelling, larger fibre deformation mechanisms as lumen opening or twisting phenomena, or changes at the network scale because of relaxation of stresses initiated at drying. Therefore, the difference 
between $C$ and $C_{t}$ may be considered as an additional storage capacity due to water-induced deformations of the fibre network. Values of $C-C_{t}$ are presented in Tables 2 and 3. For MFC-papers, they were almost $40 \%$ lower compared with refined papers in the same range of bulk. This suggested that deformations induced by water absorption of fibres were less significant in MFC-papers. A possible explanation is that when microfibrils were wetted, they formed a hydrogel with high viscosity even at low consistency (Schenker et al. 2019). The presence of this "MFC paste" at the inter-fibre contacts might limit the occurrence of large deformation mechanisms. Indeed, the resulted high capillary forces might maintain the area of inter-fibre contacts (Tejado and van de Ven 2010; Persson et al. 2012; Hirn and Schennach 2015) and prevent the stress relaxation phenomena. Same mechanisms could be at work in refined papers because of the presence of fines and fibrils at inter-fibre contacts but to a lesser extent.

The strategy of fractionating and only refining the accepts fraction presented in this work could help to improve the compromise between absorbency capacity and strength. Indeed, the $A$ fraction could give a high initial storage capacity as the $A$ fibres could form a stiff network that can "carry" the whole structure, as it is observed when mixing mechanical and chemical pulps (Fernandez and Young 1994). The fibrillated fibres and fines generated by refining the $B$ fraction might be numerous enough to enhance inter-fibre bonding but too few to allow large fibre deformation mechanisms to occur.

\section{CONCLUSIONS}

1. An experimental study was conducted to determine how pulp fractionation, refining or addition of microfibrillated cellulose (MFC) affected the absorbency capacity and tensile strength of $33 \mathrm{~g} / \mathrm{m}^{2}$ model papers. The compromise of properties was found to be better when fibres were fractionated/refined than when MFC was added.

2. The water storage capacity due to water-induced deformations of the fibre network could be lower in MFC-papers. By forming a high viscosity gel at inter-fibre contacts, MFC could limit the occurrence, upon rewetting, of large deformation mechanisms of fibres and network.

3. Some first results suggested that fractionating and only refining the base fraction could be a relevant approach to optimize the compromise of properties. But further investigations are needed.

\section{ACKNOWLEDGMENTS}

The authors acknowledge the financial support from CTP. Christian Berek, Priscilla Marquet, Mélanie Lehmann, Xavier Rousset, and Adrien Soranzo are thanked for experimental work. 


\section{REFERENCES CITED}

Abedsoltan, H. (2017). Meso-Scale Wetting of Paper Towels, Ph.D. Dissertation, Miami University, Oxford, Ohio.

Ankerfors, M., Lindström, T., and Glad Nordmark, G. (2017). "The effects of different types of wet-end added microfibrillated celluloses on the properties of paper made from bleached kraft pulp," Nordic Pulp and Paper Research Journal 32(3), 336-345. DOI: 10.3183/NPPRJ-2017-32-03-p336-345

Antonsson, S., Mäkelä, P., Fellers, C., and Lindström, M. E. (2009). "Comparison of the physical properties between hardwood and softwood pulps," Nordic Pulp and Paper Research Journal 24(4), 409-414. DOI: 10.3183/NPPRJ-2009-24-04-p409-414

De Assis, T., Reisinger, L. W., Pal, L., Pawlak, J., Jameel, H., and Gonzalez, R. W. (2018). "Understanding the effect of machine technology and cellulosic fibers on tissue properties-A review," BioResources 13(2), 4593-4629.

DOI: 10.15376/biores.13.2.4593-4629

De Assis, T., Pawlak, J., Pal, L., Jameel, H., Reisinger, L. W., Kavalew, D., Campbell, C., Pawlowska, L., and Gonzalez, R. W. (2020). "Comparison between uncreped and creped handsheets on tissue paper properties using a creping simulator unit," Cellulose 27(10), 5981-5999. DOI: 10.1007/s10570-020-03163-0

Fernandez, E. O., and Young, R. A. (1994). "An explanation for the deviation from linearity in properties of blends of mechanical and chemical pulps," Tappi Journal 77(3), 221-224.

Gharehkhani, S., Sadeghinezhad, E., Kazi, S. N., Yarmand, H., Badarudin, A., Safaei, M. R., and Zubir, M. N. M. (2015). "Basic effects of pulp refining on fiber properties-A review," Carbohydrate Polymers 115, 785-803.

DOI:10.1016/J.CARBPOL.2014.08.047

Gigac, J., and Fišerová, M. (2008). "Influence of pulp refining on tissue paper properties," Tappi Journal 7(8), 27-32.

He, J., Batchelor, W. J., and Johnston, R. E. (2003). "The behavior of fibers in wet pressing," Tappi Journal 2(12), 27-31.

Hirn, U., and Schennach, R. (2015). "Comprehensive analysis of individual pulp fiber bonds quantifies the mechanisms of fiber bonding in paper," Scientific Reports 5(1), 1-9. DOI:10.1038/SREP10503

Hsieh, Y. L. (1995). "Liquid transport in fabric structures," Textile Research Journal 65(5), 299-307. DOI:10.1177/004051759506500508

Hubbe, M. A., Ayoub, A., Daystar, J. S., Venditti, R. A., and Pawlak, J. J. (2013). "Enhanced absorbent products incorporating cellulose and its derivatives: A review," BioResources 8(4), 6556-6629. DOI: 10.15376/biores.8.4.6556-6629

Huber, P., Carré, B., Kumar, S., and Lecourt, M. (2018). “Optimum strategies for pulp fractions refining," Nordic Pulp and Paper Research Journal 33(1), 3-11. DOI:10.1515/NPPRJ-2018-3012

Kullander, J., Nilsson, L., and Barbier, C. (2012). "Evaluation of furnishes for tissue manufacturing; suction box dewatering and paper testing," Nordic Pulp and Paper Research Journal 27(1), 143-150. DOI:10.3183/NPPRJ-2012-27-01-p143-150

Lecourt, M., Soranzo, A., and Petit-Conil, M. (2011). "Refining of Pine radiata and eucalyptus kraft pulps assisted with commercial laccase mediator systems," O PAPEL 72(8), 57-61. 
Meyer, V., Tapin-Lingua, S., Da Silva Perez, D., Arndt, T., and Kautto, J. (2012, June). "Technical opportunities and economic challenges to produce nanofibrillated cellulose in pilot scale: NFC delivery for applications in demonstrations trials," in: SUNPAP EU Project-Final Conference, Milan, Italy, 19-20.

Morais, F. P., Carta, A. M., Amaral, M. E., and Curto, J. M. (2021). "Micro/nanofibrillated cellulose (MFC/NFC) fibers as an additive to maximize eucalyptus fibers on tissue paper production," Cellulose 1-19. DOI:10.1007/s10570-021-03912-9

Niskanen, K. (1998). Book 16: Paper Physics, Helsinki, Fapet Oy.

Niskanen, K. (Ed.). (2011). Mechanics of paper products. Walter de Gruyter.

Persson, B. N., Ganser, C., Schmied, F., Teichert, C., Schennach, R., Gilli, E., and Hirn, U. (2012). "Adhesion of cellulose fibers in paper," Journal of Physics: Condensed Matter 25(4), article no. 045002. DOI:10.1088/0953-8984/25/4/045002

Pulkkinen, I., and Fiskari, J. (2008). "The use of fibre wall thickness data to predict handsheet properties of eucalypt pulp fibres," O Papel 69(10), 71-85.

Sayeb, S., Hassen, M. B., and Sakli, F. (2013). "Modelling absorption capacity performance of hygienic product," Open Journal of Applied Sciences 3(2). DOI:10.4236/OJAPPS.2013.32023

Schenker, M., Schoelkopf, J., Gane, P., and Mangin, P. (2019). "Rheology of microfibrillated cellulose (MFC) suspensions: influence of the degree of fibrillation and residual fibre content on flow and viscoelastic properties," Cellulose 26(2), 845860. DOI: $10.1007 / \mathrm{s} 10570-018-2117-4$

Steadman, R., and Luner, P. (1985). "The effect of wet fiber flexibility on sheet apparent density," Papermaking Raw Materials 1, 311-337.

Tejado, A., and van de Ven, T. G. (2010). "Why does paper get stronger as it dries?" Materials Today 13(9), 42-49. DOI: 10.1016/S1369-7021(10)70164-4

Zambrano, F., Wang, Y., Zwilling, J. D., Venditti, R., Jameel, H., Rojas, O., and Gonzalez, R. (2021). "Micro-and nanofibrillated cellulose from virgin and recycled fibers: A comparative study of its effects on the properties of hygiene tissue paper," Carbohydrate Polymers 254, article no. 117430.

DOI:10.1016/J.CARBPOL.2020.117430

Article submitted: September 21, 2021; Peer review completed: November 14, 2021; Revised version received and accepted: January 5, 2022; Published: January 12, 2022. DOI: 10.15376/biores.17.1.1507-1517 